\title{
Aortic Coarctation a Systemic Vessel Disease- Insights from Magnetic Resonance Imaging
}

\author{
Joachim G. Eichhorn ${ }^{1}$ Sebastian Ley ${ }^{20} \quad$ Florian Kropp $^{3} \quad$ Christian Fink $^{4}$ Konrad Brockmeier ${ }^{5}$ \\ Tsvetomir Loukanov ${ }^{6}$ Julia Ley-Zaporozhan ${ }^{7}$
}

${ }^{1}$ Children's Hospital, Klinikum Leverkusen, Leverkusen, Germany

${ }^{2}$ Diagnostische und Interventionelle Radiologie, Chirurgisches Klinikum München Süd, Munich, Germany

3 Department of Paediatric Cardiology, University Children's Hospital, Heidelberg, Germany

${ }^{4}$ Department of Radiology, Klinikum Celle, Celle, Germany

5 Department of Paediatric Cardiology, University Children's Hospital, Cologne, Germany

${ }^{6}$ Section of Pediatric Heart Surgery Cardiac Surgery, Department of Cardiothoracic Surgery, University Hospital, Heidelberg, Germany

7 Department of Radiology, Ludwig Maximilians Universität München, Munich, Germany

Thorac Cardiovasc Surg 2019;67(Suppl S4):e1-e10.

\begin{abstract}
Address for correspondence Prof. Dr. Sebastian Ley, Department of Diagnostic and Interventional Radiology, Chirurgisches Klinikum München Süd, Am Isarkanal 30, Munich 81379, Germany

(e-mail: ley@gmx.de; ley@radiologie-ley.de).
\end{abstract}

\begin{abstract}
Keywords

- aortic coarctation

- surgical repair

- hypertension

- arch geometry

- compliance

- systemic vessel disease

Background Even after successful aortic coarctation (CoA) repair, hypertension causes premature morbidity and mortality. The mechanisms are not clear. The aim was to evaluate elastic wall properties and aortic morphology and to correlate these results with severity of restenosis, hypertension, aortic arch geometry, noninvasive pressure gradients, and time and kind of surgical procedure.

Methods Eighty-nine patients ( $17 \pm 6.3$ years) and 20 controls ( $18 \pm 4.9$ years) were examined using magnetic resonance imaging (MRI). In addition to contrast-enhanced MR angiography and flow measurements, CINE MRI was performed to assess the relative change of aortic cross-sectional areas at diaphragm level to calculate aortic compliance (C). Results Fifty-four percent of all patients showed hypertension ( $>95$ th percentile), but more than half of them had no significant stenosis (defined as $\geq 30 \%$ ). $C$ was lower in CoA than in controls $\left(3.30 \pm 2.43\right.$ vs. $\left.4.67 \pm 2.21\left[10^{-5} \mathrm{~Pa}^{-1} \mathrm{~m}^{-2}\right] ; p=0.024\right)$. Significant differences in compliance were found between hyper- and normotensive patients $(2.61 \pm 1.60$ vs. $4.11 \pm 2.95 ; p=0.01)$, and gothic and Romanesque arch geometry $(2.64 \pm 1.58$ vs. $3.78 \pm 2.81 ; p=0.027)$. There was a good correlation between $C$ and hypertension $(r=0.671 ; p<0.01)$, but no correlation between $C$ (and hypertension) and time or kind of repair, restenosis, or pressure gradients.

Conclusion The decreased compliance, a high rate of hypertension without restenosis, and independency of time and kind of repair confirm the hypothesis that CoA may not be limited to isthmus region but rather be a widespread (systemic) vascular anomaly at least in some of the CoA patients. Therefore, aortic compliance should be assessed in these patients to individually tailor treatment of CoA patients with restenosis and/or hypertension.
\end{abstract}

received

April 22, 2019

accepted after revision

August 12, 2019
Issue Theme Pediatric and

Congenital Cardiology

DOI https://doi.org/

10.1055/s-0039-1697915.

ISSN 0171-6425.
(C) 2019 Georg Thieme Verlag KG Stuttgart · New York
License terms

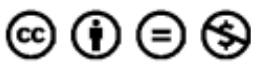




\section{Introduction}

Aortic coarctation $(\mathrm{CoA})$ is a common congenital malformation with an incidence of 8 to 10/10,000 and is therefore one of the five most frequent congenital heart diseases. Patients with an uncorrected CoA have a mean life expectancy of only 35 years. ${ }^{1}$ Surgery has been available to repair this defect since more than half a century and now interventional catheter methods of treatment are available. CoA therapy during early childhood should prevent progressive cardiac failure and reduces the risk of later hypertension ${ }^{2-4}$. While often considered to be cured, patients with repaired CoA frequently have premature morbidity and even mortality. ${ }^{5}$ Long-term follow-up studies showed, that also these patients have a reduced life expectancy. In previous studies, 50 years after surgery, only little more than two-thirds of the patients are alive, ${ }^{6-8}$ and in the COAFU trial, the late mortality rate was $6 \%$ with a median age of 41 years. ${ }^{9}$ Systemic arterial (residual or recurrent) hypertension has been proposed as the major reason for premature morbidity and mortality after aortic $\mathrm{CoA}$ repair due to cardiovascular complication. $2,3,7,8,10-12$ The pathophysiology of hypertension that occurs also late after CoA repair is not yet fully understood. Hypertension may be associated with anatomical and functional changes in the arterial vasculature. Restenosis or residual stenosis accounts for only a minority of cases of postoperative hypertension. ${ }^{5,13,14}$ Systemic hypertension can occur after repair and may be due to residual or recurrent coarctation, but even patients with a successful repair may develop hypertension.

It was hypothesized that abnormalities of the aortic wall may impair aortic elasticity and compliance. This idea is consistent with other findings of a stiffer transverse aortic arch in patients with CoA and suggests that the defect may not be limited to the small area of coarctation but may be a widespread vascular anomaly. ${ }^{15}$

The aim of this study was to assess the prevalence of abnormal elastic wall properties in patients after CoA repair (remote of the region of any treatment/intervention) and aortic arch geometry, and second, to evaluate the relation of these results with the severity of restenosis, hypertension, noninvasive pressure gradients, and time and kind of surgical procedure.

\section{Materials and Methods}

\section{Patients}

Eighty-nine patients (mean age $17 \pm 6.3$ years; median 7 , range 3-37 years: end-to-end anastomosis [ $n=45]$, patch plastic [15], subclavian flap [9], others [20]: $40 \%$ treated in first year of age) and 20 controls ( $18 \pm 4.9$ years) were examined prospectively.

Over a period of 10 years (between June 2002 and March 2012 a total of 192 patients with CoA were operated), 89 patients with previously surgical repaired $\operatorname{CoA}(n=79 ; 89 \%)$ or native $\operatorname{CoA}(n=10 ; 11 \%)$ were included in this prospective study. There were 59 males and 30 females (mean age \pm standard deviation [SD], $17 \pm 6.3$ years). Forty percent of the patients were treated in the first year of life. The median time between initial repair and magnetic resonance imaging
(MRI) was 14 years (range 1.5-24 years). In 45/79 patients (57\%), the first surgical repair consisted of resection and endto-end anastomosis, and in 15 patients (19\%) a patch graft aortoplasty. Twelve patients had undergone subclavian flap technique $(n=9 ; 11 \%)$ or a primary tube interposition graft ( $n=3 ; 4 \%)$. Three patients (4\%) were treated interventionally (balloon angioplasty without stent placement) once or twice before their last surgical correction. Two patients had a resection and ascendo-descendo anastomosis (3\%), and two others an unknown first procedure (3\%).

Ten patients with hypertension were on antihypertensives ( 4 in monotherapy with a $\beta$ blocker and 2 with an angiotensin-converting enzyme inhibitor and 4 with a combination of both) and no one with normotension.

The control group consisted of 20 healthy volunteers ( $18 \pm 4.9$ years, median 17 , range $9-26$ ).

Informed consent was obtained from all participants. Participants less than 18 years of age assented to the participation and their legal representatives consented. The study protocol was approved by the local ethics committee.

\section{Magnetic Resonance Imaging}

MRI was performed on 1.5 T whole-body MR systems (Symphony Magnetom [the first 32 patients and the whole control group] and Avanto Magnetom [the last 57 patients], Siemens Medical Solutions, Erlangen, Germany). For signal reception, a standard body-phased array coil was used.

\section{The Examination Protocol}

Localization of the aorta (true fast imaging with steady precession) in transversal, coronal, and sagittal orientation.

Two-dimensional (2D) CINE MRI (fast low angle shot [FLASH]) as "bright blood" technique of the aorta in transversal slice orientation, perpendicular angulated to the vessel at the level of diaphragm ( - Fig. 1) to calculate aortic compliance (C) with following technical details:

- Symphony: TE $=4 \mathrm{~ms}, \mathrm{TR}=18 \mathrm{~ms}$, FOV $180 \times 180 \mathrm{~mm}^{2}$, matrix $192 \times 256$ pixel, slice thickness $6 \mathrm{~mm}$, flip angle $\alpha=40^{\circ}$.

- Avanto: TE $=3.7 \mathrm{~ms}, \mathrm{TR}=72 \mathrm{~ms}$, FOV $180 \times 180 \mathrm{~mm}^{2}$, matrix $312 \times 384$ pixel, slice thickness $3 \mathrm{~mm}$, flip angle $\alpha=15^{\circ}$.

The sequence was prospectively electrocardiogram triggered and performed in an inspiratory breath-hold. This sequence was performed in 76 patients at the level of the diaphragm and in 13 at a more proximal level, but not higher than the bifurcation level of the pulmonary arteries (these 13 patients were excluded for the comparison with the volunteers). In these 13 patients, the MR technicians planned the compliance measurement at the wrong anatomical level and the measurements could not be redone.

\section{Two-Dimensional Phase-Contrast Flow Measurements (Pre-, In-, and Poststenoses)}

The blood flow velocity measurements were performed with a flow sensitive, phase-contrast (PC) gradient echo pulse 


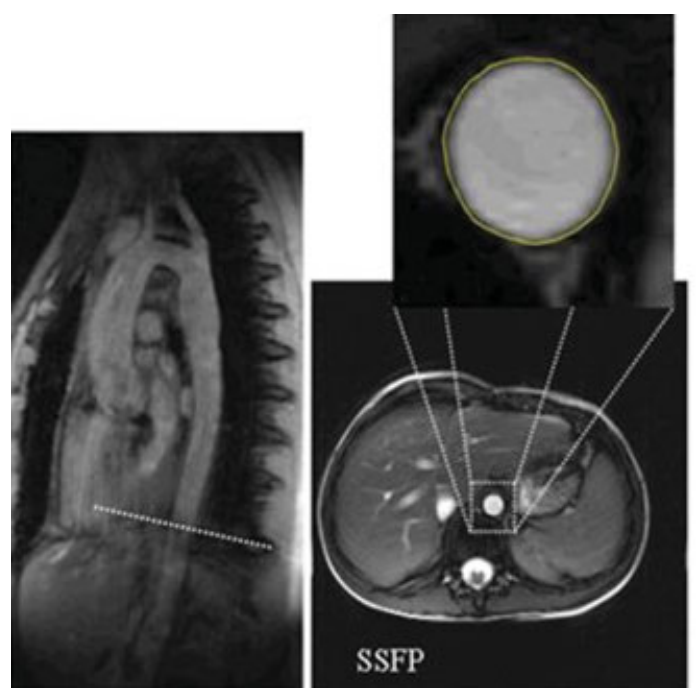

\section{Area over the time}

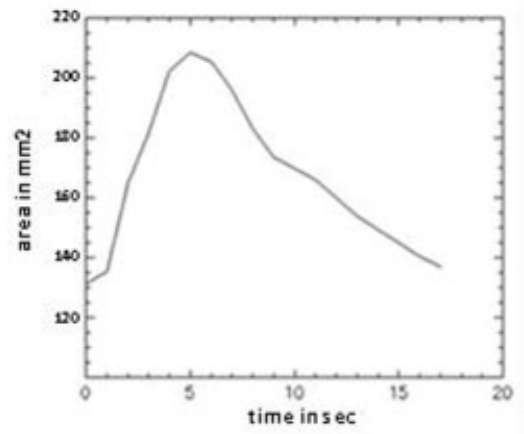

Fig. 1 (A) Sagittal image of the aorta for planning transversal the CINE sequence at the level of the diaphragm (B). (C) Enlarged visualization of the region of interest in the descending aorta with region of interest (ROI) placed for assessment of temporal change of area over time (D).

sequence using the following image parameters: FLASH 2D, echo time/repetition time $=4 / 9 \mathrm{~ms}$, flip angle $30^{\circ}$, field of view $390 \mathrm{~mm}$, matrix $192 \times 256$, slice thickness $6 \mathrm{~mm}, 25$ to 39 phases per heart cycle, and high-velocity encoding (VENC) typically of $500 \mathrm{~cm} / \mathrm{s}$. The PC-MRI sequences were performed during free breathing. Prior to the quantitative throughplane flow measurements, in-plane flow measurements were performed along the course of the aorta to visualize flow jets and to facilitate positioning of subsequent throughplane measurements. In general, one through-plane PC flow measurement was made in the proximal descending aorta (aortic isthmus, immediately distal to a stenosis). All flow measurements were orientated perpendicular to the main flow jet. If no jet was visible, measurements were orientated perpendicular to the aorta.

For visualization of the aorta, a contrast-enhanced MRI angiography three-dimensional (3D) MR FLASH (TE $=1.8 \mathrm{~ms}$, $\mathrm{TR}=4.6 \mathrm{~ms}$, matrix: $215 \times 512$ pixel, slice thickness $1.25 \mathrm{~mm}$, flip angle $\alpha=50^{\circ}$ using $0.2 \mathrm{mmol} / \mathrm{kg}$ KG gadolinium-diethylenetriamine pentaacetic acid contrast agent [Magnevist, Schering AG, Berlin, Germany]) were performed in patients.

\section{Compliance}

Compliance (C), as a parameter of distensibility, can be assessed with different methods using MRI. ${ }^{16,17}$ In our study, aortic compliance (C) was calculated by assessing aortic distensibility as a relative change in the aortic cross-sectional areas during cardiac systole and diastole, taking into account blood pressure ${ }^{18}$ :

$\Delta A=$ Difference between maximum area $\left(A_{\max }\right)\left[\mathrm{m}^{2}\right]$ and minimum $\left(A_{\min }\right)\left[\mathrm{m}^{2}\right]$ of the aorta over the cardiac cycle. $\Delta P=$ Blood pressure amplitude (systolic - diastolic blood pressure) $\left[\mathrm{Pa}^{-1}\right]$.

Finally, these results were calculated in relation to body surface area. All measurements were positioned perpendicular to the descending aorta at the level of the diaphragm (-Fig. 1). Evaluation was done using an in-house developed software (based on IDL version 6.0 Win 32) as previously described. ${ }^{17}$ Contours were placed manually by an experienced observer. The method has already been evaluated for its inter- and intraobserver variability. ${ }^{17}$

\section{Velocity Measurements}

The analysis of the velocity measurements was performed with a dedicated evaluation software available on the MR scanner (ARGUS) and included the calculation of the mean and peak blood flow velocity and the flow volume. Similar to previous studies, $\Delta P$ was estimated from peak velocities measured with MR PC velocity mapping using a simplified or modified Bernoulli equation. ${ }^{19-23}$

\section{Morphology of the Aortic Arch}

The 3D-MR angiography image data sets were postprocessed (maximum intensity projection, multiplanar reconstruction, and volume rendering) (3D tool of Siemens Syngo Workplace). Two observers evaluated the image data in consensus classifying the presence and severity of CoA and the presence of collateral arteries. The grade of CoA was quantified by calculating percent stenosis of perpendicular angulated cross-section area of the stenosis and at a vessel segment distal to the stenosis and near the diaphragm. A significant stenosis was defined as luminal narrowing $>30 \%$.

Assessment of the geometry of the aortic arch was done by putting the width of the aortic arch in relation to the height. The width was defined as the transverse distance between the ascending and descending aorta (center of the vessel) at the level of the pulmonary arteries. The height was determined as the largest distance of the width of the aortic arch to the aortic $\operatorname{arch}$ (-Fig. 2). It has to be noted that no patient presented with a hypoplastic arch. As a limitation of the simplified height/ width ratio it has to be mentioned that any form of tortuous arch geometry is not acknowledged. However, this aspect is not yet an established feature in patients with coarctation.

Based on previously defined definitions, a height/width ratio of $>0.745$ was called gothic, a height/width ratio of $\leq 0.745$ was called Romanesque arch. ${ }^{24}$ 

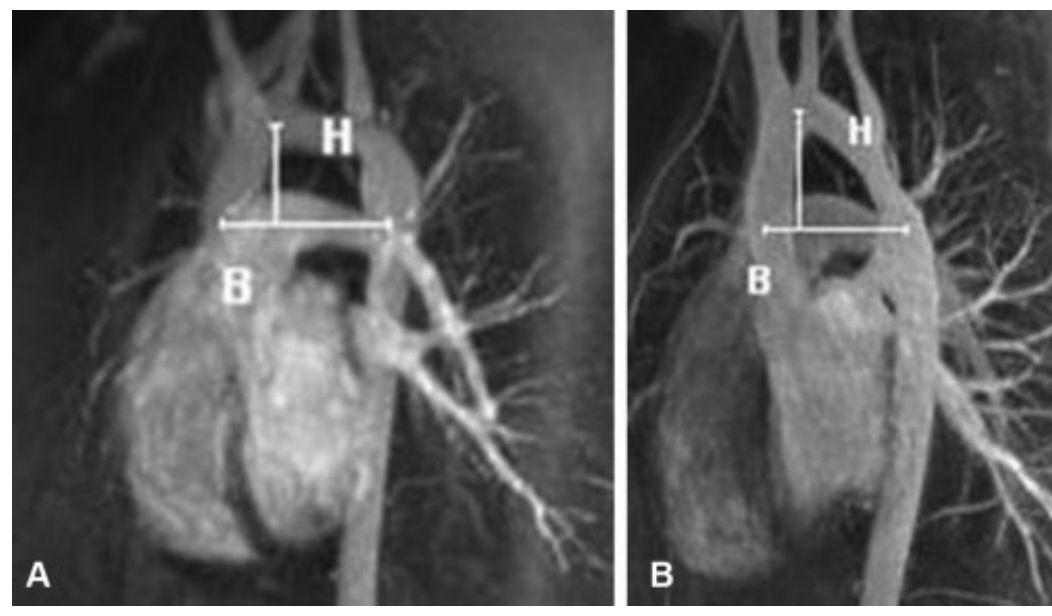

Fig. 2 Contrast-enhanced magnetic resonance (MR) angiography of the aortic arch (maximum intensity projection). (A) Romanesque arch. (B) Gothic arch. "B" marks the width as the distance between the ascending and descending aorta (center of the vessel) at the level of the pulmonary arteries. The height " $\mathrm{H}$ " was determined as the largest distance of the width of the aortic arch to the aortic arch.

\section{Echocardiography}

Echocardiography was performed with a Vivid 7 ultrasound system (GE Healthcare, Chalfont St. Giles, United Kingdom). Parasternal long- and short-axis scanning was performed and was used to measure left ventricular dimensions and aortic annulus size, according to the recommendations of the American Society of Echocardiography. ${ }^{25}$ Apical and subcostal views were used to assess flow velocity across the aortic valve. Left ventricular systolic function was assessed by measurements of shortening fraction and ejection fraction as index of cardiac function.

\section{Blood Pressure Measurement}

Systolic and diastolic blood pressure was measured with Dinamap Pro Care 100 (GE Healthcare) at the right arm and leg before the MRI measurements. Age-related normative data for normal blood pressure in children and adolescents was used, regarding values greater than the 95th percentile as hypertensive (values from measurements of the right arm). ${ }^{26}$

In patients with an indication for an invasive catheterization, these pressure data were included into the evaluation. No catheterizations were performed within the study protocol.

\section{Statistical Analysis}

Analysis was performed using SPSS 15.0 (SPSS Inc. Chicago, Illinois, United States). Results are expressed by mean and range. $t$-Test was performed to compare the aortic compliance between patients and healthy controls, normotensive and hypertensive patients, as well as between different arch types. A $p$-value of $\leq 0.05$ was considered to indicate significance unless specified otherwise. Compliance of patients and controls plotted against age were presented as a nonlinear power regression line.

For the correlation of the hemodynamic parameters obtained from MRI with the clinical hemodynamic parameters, a Spearman's correlation was performed. Differences were tested for significance using a two-sided $t$-test. Significance was assumed with $p \leq 0.05$.

\section{Results}

Two-thirds of all patients had an elevated blood pressure (> 90th percentile). Slightly more than half $(54 \%)$ showed hypertension ( $>95$ th percentile), but more than half of them had no significant stenosis (defined as $\geq 30 \%$ ). The compliance was lower in the patients group than in the controls $\left(3.30 \pm 2.43\right.$ vs. $\left.4.67 \pm 2.21\left[10^{-5} \mathrm{~Pa}^{-1} \mathrm{~m}^{-2}\right] ; p=0.024\right)$ (-Table 1).

In both groups compliance is decreasing with increasing patients' age (-Fig. 3 ).

The 10 patients on antihypertensives had the lowest values of compliance in comparison to the controls 2.51 to $4.67\left(10^{-5} \mathrm{~Pa}^{-1} \mathrm{~m}^{-2}\right)(p<0.01)$.

Significant differences were found between hyper- and normotensive patients $(2.61 \pm 1.60$ vs. $4.11 \pm 2.95 ; p=0.01)$. No difference was found between normotensive patients and controls (-Fig. 4, - Table 2).

Following a regression analysis, the compliance was found to be a highly significant predictor for the systolic blood pressure and the presence of hypertonia $(p<0.01$ for the

Table 1 Comparison of the compliance values between patients and healthy volunteers (with aortic measurements at the level of the diaphragm)

\begin{tabular}{|l|l|l|l|}
\hline & Patients & Volunteers & p-Value \\
\hline Number $[n]$ & 76 & 20 & - \\
\hline Age range $[\mathrm{y}]$ & $3-37$ & $9-26$ & 0.892 \\
\cline { 1 - 3 } Age mean \pm SD $[\mathrm{y}]$ & $17.7 \pm 6.2$ & $17.5 \pm 4.9$ & \\
\cline { 1 - 3 } $\begin{array}{l}\text { Compliance/BSA } \\
\text { range }\left[10^{-5} \mathrm{~Pa}^{-1} \mathrm{~m}^{-2}\right]\end{array}$ & $0.56-16.94$ & $2.30-12.50$ & 0.024 \\
\cline { 1 - 2 } $\begin{array}{l}\text { Compliance/BSA } \\
\text { mean } \pm \mathrm{SD} \\
{\left[10^{-5} \mathrm{~Pa}^{-1} \mathrm{~m}^{-2}\right]}\end{array}$ & $3.30 \pm 2.43$ & $4.67 \pm 2.20$ & \\
\hline
\end{tabular}

Abbreviations: BSA, body surface area; SD, standard deviation. 


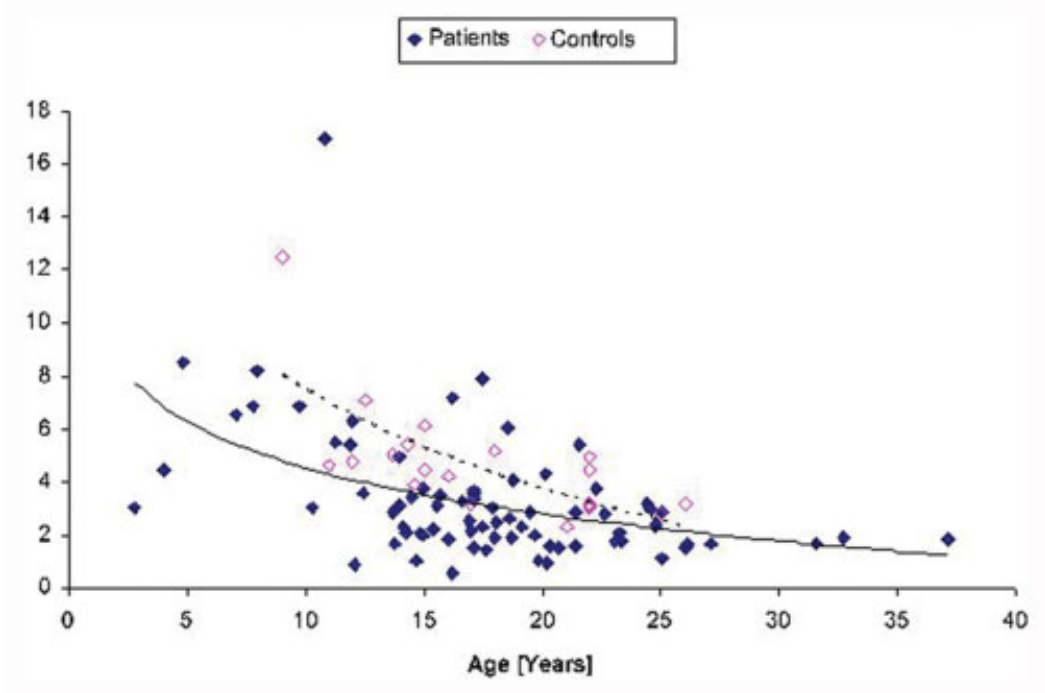

Fig. 3 Compliance/body surface area (BSA) of all patients and volunteers according to their age. Exponential regression to visualize the effect (solid line, patients; dotted line, volunteers).

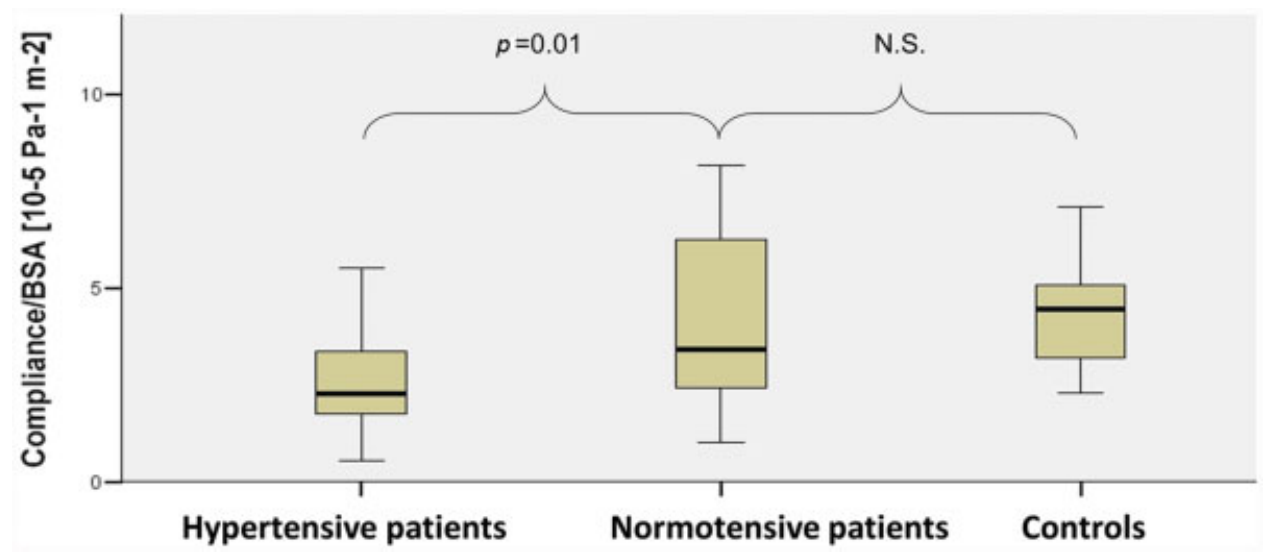

Fig. 4 Boxplot diagram of the compliance/body surface area (BSA) of the hypertensive and normotensive patients and controls. N.S., not significant.

Table 2 Subgroup comparison between the hypertensive and normotensive patients (patients with compliance measurements at the level of the diaphragm included)

\begin{tabular}{|c|c|c|c|}
\hline & $\begin{array}{l}\text { Hypertensive } \\
\text { patients }\end{array}$ & $\begin{array}{l}\text { Normotensive } \\
\text { patients }\end{array}$ & $p$-Value \\
\hline Number $[n]$ & 41 & 35 & - \\
\hline $\begin{array}{l}\text { Median age } \\
\text { and range [y] }\end{array}$ & $17.1 ; 3-37$ & $16.9 ; 4-25$ & - \\
\hline Mean age [y] & $18.5 \pm 6.8$ & $16.8 \pm 5.4$ & \\
\hline \multicolumn{4}{|l|}{ Gender } \\
\hline $\begin{array}{l}\text { Male } \\
\text { Female }\end{array}$ & $\begin{array}{l}30 \\
11\end{array}$ & $\begin{array}{l}21 \\
14\end{array}$ & - \\
\hline $\begin{array}{l}\text { Compliance/ } \\
\text { BSA range } \\
{\left[10^{-5} \mathrm{~Pa}^{-1} \mathrm{~m}^{-2}\right]}\end{array}$ & $0.56-8.51$ & $1.02-16.94$ & \multirow[t]{2}{*}{0.01} \\
\hline $\begin{array}{l}\text { Compliance/ } \\
\mathrm{BSA} \text { mean } \pm \text { SD } \\
{\left[10^{-5} \mathrm{~Pa}^{-1} \mathrm{~m}^{-2}\right]}\end{array}$ & $2.61 \pm 1.60$ & $4.11 \pm 2.95$ & \\
\hline
\end{tabular}

Abbreviations: BSA, body surface area; SD, standard deviation. systolic blood pressure group and $p=0.032$ for the blood pressure group).

\section{Compliance and Aortic Arch Geometry}

The control group showed a Romanesque arch.

The patients were divided into two groups of varying aortic arch geometry. The patients with gothic arches showed a lower compliance than patients with Romanesque arches $\left(2.64 \pm 1.58\right.$ vs. $\left.3.78 \pm 2.81\left[10-5 \mathrm{~Pa}^{-1} \mathrm{~m}^{-2}\right] ; p=0.027\right)$. Also, a significant difference was found between the patients with gothic arches and the controls $(p<0.01)$. The difference between patients with Romanesque arches and controls was not significant $(p=0.213$ ) (-Table 3, - Fig. 5).

\section{Correlation of Compliance to Blood Pressure, Degree of Stenosis, Pressure Gradient, Type of Repair, and Timing}

The blood pressure of the patients was (mean) 132/67 mm Hg ( $\mathrm{SD} \pm 20 / 11 \mathrm{~mm} \mathrm{Hg}$ ) assessed at the upper extremity and 129/ $66 \mathrm{~mm} \mathrm{Hg}(\mathrm{SD} \pm 23 / 10 \mathrm{~mm} \mathrm{Hg})$ at the lower extremity. A good correlation between systolic and diastolic blood pressure as 
Table 3 Comparison between patients with different architecture of the aortic arch (patients included with compliance measurements at the level of the diaphragm, $n=76$ ) with controls

\begin{tabular}{|l|l|l|l|}
\hline & $\begin{array}{l}\text { "Romanesque" } \\
\text { Height/Width } \\
\leq \mathbf{0 . 7 4 5}\end{array}$ & $\begin{array}{l}\text { "Gothic" } \\
\text { Height/Width } \\
>\mathbf{0 . 7 4 5}\end{array}$ & Controls \\
\hline Number [n] & 44 & 32 & 20 \\
\hline $\begin{array}{l}\text { Median age } \\
\text { and range [y] }\end{array}$ & $17.1 ; 3-27$ & $18.6 ; 4-37$ & $16.5 ; 9-26$ \\
\hline Mean age [y] & $16.6 \pm 5.8$ & $19.3 \pm 6.6$ & $17.5 \pm 4.9$ \\
\hline Gender & & & \\
\hline $\begin{array}{l}\text { Male } \\
\text { Female }\end{array}$ & 29 & 22 & - \\
\hline $\begin{array}{l}\text { Compliance/ } \\
\text { BSA range } \\
{\left[10^{-5} \mathrm{~Pa}^{-1} \mathrm{~m}^{-2}\right]}\end{array}$ & $1.10-16.94$ & $0.56-6.82$ & $2.30-12.50$ \\
\hline $\begin{array}{l}\text { Compliance/ } \\
\text { BSA mean } \pm \text { SD } \\
{\left[10^{-5} \mathrm{~Pa}^{-1} \mathrm{~m}^{-2}\right]}\end{array}$ & $3.78 \pm 2.81$ & $2.64 \pm 1.58$ & $4.67 \pm 2.20$ \\
\hline
\end{tabular}

Abbreviations: BSA, body surface area; SD, standard deviation.

well as blood pressure percentile and the compliance were found (-Table 4).

Only 14 patients had a systolic pressure gradient of $\geq 20 \mathrm{~mm}$ $\mathrm{Hg}$ between the upper and lower extremity indicating a significant stenosis. Eight of those had a stenosis of $>30 \%$.

There was no correlation between the compliance and the pressure gradient (by echocardiography/Doppler, heart catheter/invasive pressure measurements, or MRI/flow measurements). The degree of stenosis showed no correlation with the systolic blood pressure $(p=0.8)$ or the blood pressure percentile $(p=0.145)$.

Based on the MRI measurements (degree of stenosis [\%] = smallest diameter within the arch/diameter at the level of the diaphragm), 35 patients (39\%) showed a significant stenosis ( $>30 \%$ ), 4 of those even a stenosis $>60 \%$. Fifty-four patients (61\%) showed a nonrelevant stenosis, of those 20 patients had a stenosis $>10 \%$. Twenty-seven patients (30\%) suffered from hypertension ( $\geq 90$ blood pressure percentile) and had a significant stenosis. Eight patients (9\%) had a stenosis but no hypertension, and 18 patients (20\%) no
Table 4 Correlation between the compliance and blood pressure

\begin{tabular}{|l|l|l|l|}
\hline & $\begin{array}{l}\text { Systolic } \\
\text { blood } \\
\text { pressure }\end{array}$ & $\begin{array}{l}\text { Diastolic } \\
\text { blood } \\
\text { pressure }\end{array}$ & $\begin{array}{l}\text { Systolic } \\
\text { blood } \\
\text { pressure } \\
\text { percentiles }\end{array}$ \\
\hline $\begin{array}{l}\text { Ratio of correlation } \\
\text { coefficient to } \\
\text { compliance }\end{array}$ & 0.671 & 0.299 & 0.445 \\
\hline $\begin{array}{l}\text { Level of } \\
\text { significance, } p\end{array}$ & $<0.01$ & $<0.01$ & $<0.01$ \\
\hline
\end{tabular}

hypertension and no stenosis. Thirty-six patients had hypertension without stenosis.

The degree of stenosis showed no correlation with the compliance $(p=0.965)$. The 35 patients with significant stenosis showed a reduced compliance compared with the control group (3.58 vs. $4.67\left[10^{-5} \mathrm{~Pa}^{-1} \mathrm{~m}^{-2}\right]$ ), without reaching significance. Forty percent of patients with significant stenosis (14 of 35 patients) showed a normal compliance ( $\geq$ 5th percentile) (-Fig. 6 ).

\section{Timing of Surgery}

Twenty-five patients were operated within the first year of life (33\%, based on 76 patients with a compliance measurement). Seven patients (9\%) were operated in their second year of life, 7 patients $(9 \%)$ in their third year, $4(5 \%)$ forth year, 8 (11\%) fifth year, and $14(18 \%)$ after the fifth year. The latest surgical procedure was performed at the age of 19. In 11 patients, the time of surgical repair could not be identified.

There was no impact of the timing of the first surgical procedure on the compliance of the aorta. In $39 \%$ of the patients, MRI showed a significant restenosis ( $\geq 30 \%$ ). Patients who were operated within their first year of life showed in 5 out of 25 cases a significant restenosis (20\%). Patients who were operated later in life showed in 24 out of 51 cases a significant restenosis (47\%).

Eighteen out of 25 patients (72\%) who were operated within their first year of life suffered from hypertension ( $>$ 90th percentile). Patients who were operated later in life (36 out of 51 patients, $71 \%$ ) showed a similar rate of hypertension.

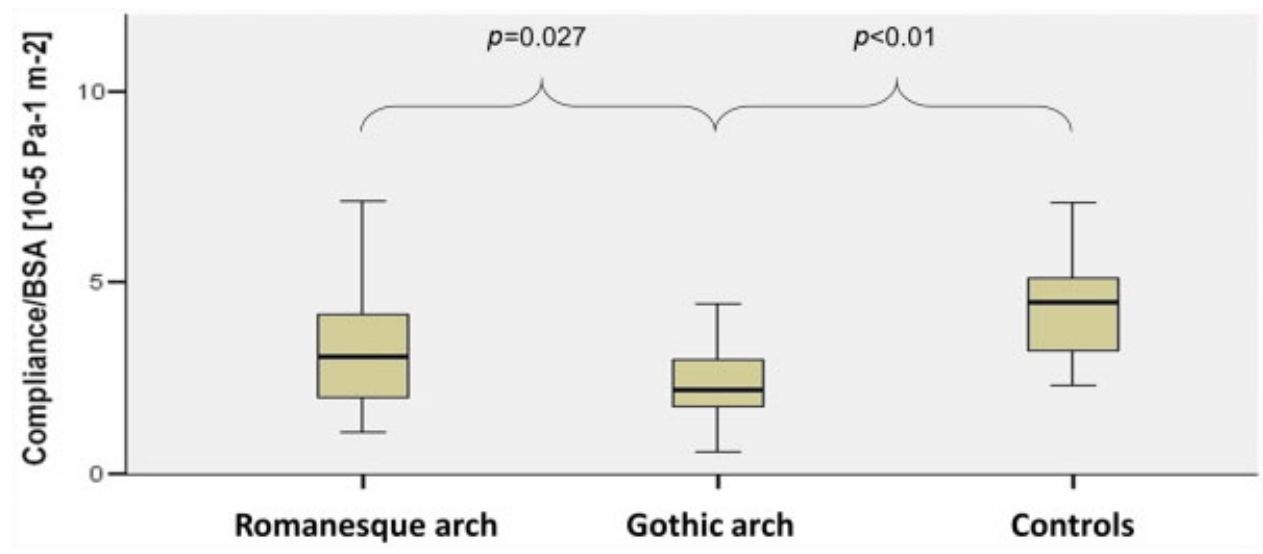

Fig. 5 Boxplot diagram showing the compliance/body surface area (BSA) with different configurations of the aortic arch and the controls $(p=0.213$, Romanesque arch vs. controls). 


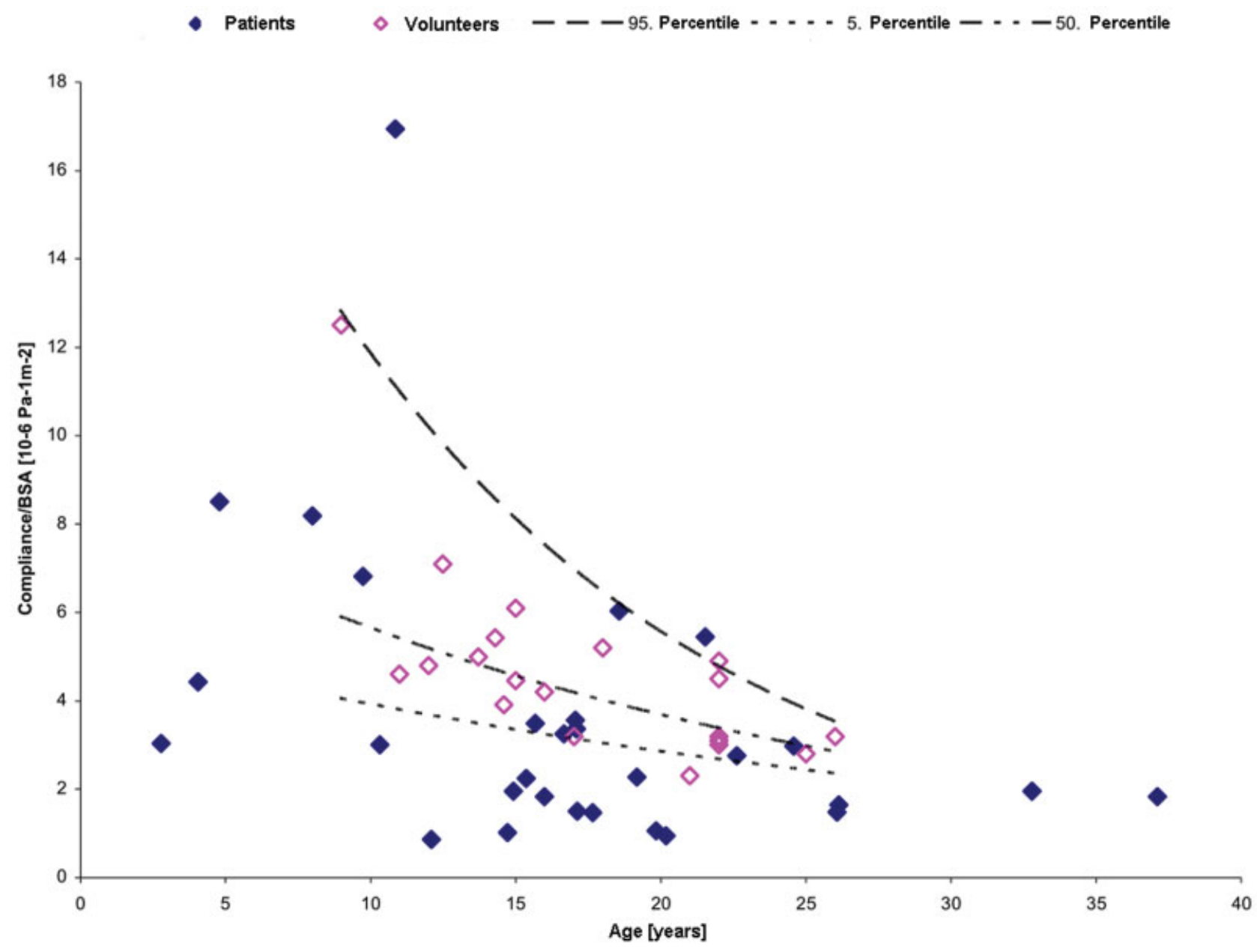

Fig. 6 Compliance/body surface area (BSA) only of patients with significant stenosis and the control group. As reference lines are the 95th and 5th percentile of the compliance of the control group as exponential regression provided.

\section{Influence of Type of Surgical Repair to Compliance}

Surgically corrected patients showed a reduced compliance compared with the controls (3.07-4.67 $\left[10^{-5}\right.$ $\left.\left.\mathrm{Pa}^{-1} \mathrm{~m}^{-2}\right], p<0.01\right)$. The type of surgical repair had no influence on the compliance or number of restenosis. However, differences between the blood pressure were found. Native $\mathrm{CoA}$ patients showed similar compliance values than the controls $\left(5.02-4.67\left[10^{-5} \mathrm{~Pa}^{-1} \mathrm{~m}^{-2}\right]\right)$.
Patients operated with tube interposition graft, subclavian flap technique, and corrected with unknown technique showed hypertension while the others were normotensive (-Table 5).

There was a good correlation between compliance and hypertension $(r=0.671 ; p<0.01)$, but no correlation between compliance (and hypertension) and time or kind of repair, restenosis, or pressure gradients.

Table 5 Influence of the type of surgical repair on blood pressure, degree of stenosis, and compliance

\begin{tabular}{|l|l|l|l|l|}
\hline & Number $[\boldsymbol{n}]$ & $\begin{array}{l}\text { Mean blood } \\
\text { pressure percentile }\end{array}$ & $\begin{array}{l}\text { Mean degree of stenosis } \\
{[\text { in \%] }}\end{array}$ & $\begin{array}{l}\text { Compliance/BSA mean } \pm \text { SD } \\
{\left[\mathbf{1 0}^{-5} \mathbf{P a}^{-1} \mathbf{m}^{-2}\right]}\end{array}$ \\
\hline Tube interposition graft & 2 & $98.5 \pm 0.71$ & $20 \pm 9.9$ & $2.28 \pm 0.81$ \\
\hline Subclavian flap & 9 & $94.7 \pm 4.3$ & $23.1 \pm 20.3$ & $2.28 \pm 0.71$ \\
\hline Other/unknown & 2 & $94.0 \pm 1.4$ & $12.5 \pm 14.5$ & $4.41 \pm 2.98$ \\
\hline Native CoA & 9 & $71.9 \pm 23.9$ & $32 \pm 14.9$ & $5.02 \pm 5.08$ \\
\hline End-to-end anastomosis & 40 & $88.9 \pm 16.0$ & $27.1 \pm 19.2$ & $3.32 \pm 1.89$ \\
\hline Patch graft aortoplasty & 12 & $88.6 \pm 16.5$ & $23.9 \pm 22.5$ & $2.34 \pm 0.88$ \\
\hline Ascendo/ descendostomy & 2 & $70 \pm 14.1$ & $12.0 \pm 17.0$ & $5.47 \pm 3.37$ \\
\hline
\end{tabular}

Abbreviations: BSA, body surface area; CoA, aortic coarctation; SD, standard deviation. 
Table 6 Multivariant analysis with type of aortic arch as constant variable

\begin{tabular}{|l|l|l|l|}
\hline Variable & Coefficient & $\boldsymbol{t}$ & $\boldsymbol{p}$-Value \\
\hline Type of repair & -0.027 & -0.308 & 0.759 \\
\hline Age at repair & -0.028 & -0.243 & 0.809 \\
\hline Systolic blood pressure & -0.200 & -0.989 & 0.326 \\
\hline $\begin{array}{l}\text { Systolic blood pressure } \\
\text { percentile }\end{array}$ & 0.244 & 1.330 & 0.188 \\
\hline Compliance & 0.054 & 0.489 & 0.627 \\
\hline
\end{tabular}

Using a multivariant analysis the influence of type of repair, age at time of repair, systolic blood pressure, blood pressure percentile, or compliance of the geometry of the aortic arch was assessed. No parameter reached significance (-Table $\mathbf{6}$ ).

\section{Discussion}

Hypertension is one of the leading cardiovascular issues in patients with treated CoA. ${ }^{27}$ It is well acknowledged that hypertension has a multifactorial origin. An increased arterial stiffness is discussed as one of the main drivers; however, even the latest review article focuses only on the prestenotic/ ascending aorta. ${ }^{27,28}$ Also, various other aspects like type of surgical repair or timing or aortic arch geometry are discussed.

In this field, still under investigation, our large population study adds some major insights. Using MRI the compliance of the aorta was assessed for the first time (to our knowledge) at the level of the diaphragm and therefore far away from the isthmic and also not in the prestenotic region and compared with healthy controls.

The technique used in our study for measuring compliance can be performed using any MR machine without special sequences or postprocessing tools.

As mentioned above, this technique was evaluated previously and found valid results. ${ }^{16-18}$ The change of area and blood pressure have influence on the compliance. We also assessed the influence of systolic pressure, diastolic pressure, and difference between systolic and diastolic pressure, at right arm and right leg. We could not find a significant correlation between these parameters and the compliance by themselves, therefore we used in all patients and subjects the blood pressure which was measured at the right arm. Still, there might be the possibility that a "delta" $\mathrm{P}$ could be driven by a high systole alone in single cases but not in all patients. In the majority of the hypertension group, systolic and also diastolic pressure increased in a similar way without any change of "delta" P.

There are newer techniques available like four-dimensional flow measurements or computational fluid dynamics simulations, even allowing for assessment of wall shear stress, but these techniques require much more acquisition time and dedicated postprocessing tools, not yet broadly available. ${ }^{29}$ Other possibilities include simulation of wall shear stress using computational fluid dynamics. ${ }^{30}$ Especially, these techniques are highly experimental and not broadly available.
Our population showed a manifest hypertension in $54 \%$ of cases, which is in the expected range for this patient collective. ${ }^{31}$ The presence of arterial hypertension correlated with a significantly decreased compliance of the aorta at the level of the diaphragm. This finding did not correlate with any other parameter like type or timing of surgical repair or degree of restenosis. This supports the hypothesis of a global systemic vascular disease..$^{30,32,33}$ Our findings are in contradiction to a previous study showing a reduced compliance of the ascending aorta was found and no change in compliance in a poststenotic segment. ${ }^{24}$ In this previous study, normotensive patients were examined and the poststenotic measurement was in the area potentially affected by surgery (scar tissue or poststenotic aortic dilatation). In our study, measurements were performed at the level of the diaphragm, remote of the location of surgery.

We confirmed the finding, that hypertension has no correlation with the degree of restenosis. ${ }^{14,34}$

On the other hand, $40 \%$ of patients with a significant restenosis ( $\geq 30 \%$ ) showed a normal compliance of the aorta. This underlines the individual aspect of the elastic properties of the aorta within the disease group of coarctation patients.

Timing of surgery had an influence on the risk of developing a restenosis, as previously suggested a younger age at the time of surgery ( $<1.5$ years) has a significantly reduced risk of development of a restenosis. ${ }^{6}$ However, in our collective, the timing of surgery had no influence on development of hypertension which is in keeping with previous reports. $2,5,14,33$

There was no correlation between degree of restenosis and systemic blood pressure or the pressure percentile. Half of all patients with hypertension had no significant stenosis. Nearly one-half of all patients had hypertension without stenosis. Conversely, $40 \%$ of patients with significant stenosis showed a normal compliance ( $\geq 5$ th percentile)

Interestingly, the type of surgical repair had a significant influence on the development of hypertension. Previously, subclavian flap repair showed worse outcome than end-toend anastomosis. ${ }^{35}$ In our population, also patients treated with a tube interposition graft showed hypertension. However, the type of surgical repair had no influence regarding the compliance or degree of restenosis.

A gothic arch geometry is a common finding in patients with coarctation. ${ }^{36}$

Regarding the influence of the arch geometry onto hypertension and compliance, mainly the ascending aorta was studied so far and a decreased compliance and increased arterial wave reflection was found for a gothic arch configuration. ${ }^{27,37}$ In a previous study, it was postulated, that a gothic arch configuration results in an increased reflection of the aortic wave with subsequent increased left ventricular hypertrophy and increased systolic pressure. ${ }^{24}$ In a more recent study, no relationship between a gothic arch configuration and coarctation index or central aortic systolic blood pressure was found. ${ }^{28}$ In our study, we found a significant lower compliance also at the level of the diaphragm in patients with a gothic arch configuration. Therefore, those patients seem to have a globally changed compliance of the aortic wall and hypertension is a subsequent result. This would also explain the differences 
between those patients with a Romanesque arch and controls -there was a nonsignificant difference in the aortic compliance. This is in keeping with another study in patients without congenital heart disease. ${ }^{38}$ Similarly, this might account for patients with coarctation not yet suffering from hypertension but already showing a reduced compliance. ${ }^{39,40}$

As limitations of our study, it has to be mentioned, that our patient population was quite inhomogeneous, that is, regarding type of surgical repair. This is a frequently seen issue in longitudinal studies in patients with congenital heart diseases. However, this heterogeneity allowed us to compare the whole bandwidth, that is, types of surgical repair and the respective outcome. That two different MRI scanner were used, is less of an issue as the temporal and spatial resolution for assessment of compliance was sufficient, as a large vessel (descending aorta) was evaluated.

Assessment of the aorta was done using a contrastenhanced angiography. Recently, it was shown that MR contrast media are deposited in the brain and thus the use of MR contrast should be handled restrictively. For visualization of the aorta, dark blood sequences and submillimetric T2-weighted images should be used.

In conclusion, we could show that at least the majority of patients with coarctation do suffer from a primary systemic vessel disease with generally reduced compliance. This seems to be a major driver for development of arterial hypertension. For patient management, it can be concluded that patients with a normal compliance might benefit from retreatment (operation and/or intervention) in case of a restenosis. Also, patients with reduced vascular compliance and no hypertension should be identified for closer blood pressure monitoring.

\section{Funding}

This work was supported by "Forschungsförderung der Medizinischen Fakultät" of the University of Heidelberg (project No.: 222-2002).

\section{Conflict of Interest}

None declared.

\section{References}

1 Campbell M. Natural history of coarctation of the aorta. Br Heart J 1970;32(05):633-640

2 Stewart AB, Ahmed R, Travill CM, Newman CG. Coarctation of the aorta life and health 20-44 years after surgical repair. Br Heart J 1993;69(01):65-70

3 Seirafi PA, Warner KG, Geggel RL, Payne DD, Cleveland RJ. Repair of coarctation of the aorta during infancy minimizes the risk of late hypertension. Ann Thorac Surg 1998;66(04):1378-1382

4 Zehr KJ, Gillinov AM, Redmond JM, et al. Repair of coarctation of the aorta in neonates and infants: a thirty-year experience. Ann Thorac Surg 1995;59(01):33-41

5 Celermajer DS, Greaves K. Survivors of coarctation repair: fixed but not cured. Heart 2002;88(02):113-114

6 Brouwer RM, Erasmus ME, Ebels T, Eijgelaar A. Influence of age on survival, late hypertension, and recoarctation in elective aortic coarctation repair. Including long-term results after elective aortic coarctation repair with a follow-up from 25 to 44 years. J Thorac Cardiovasc Surg 1994;108(03):525-531
7 Cohen M, Fuster V, Steele PM, Driscoll D, McGoon DC. Coarctation of the aorta. Long-term follow-up and prediction of outcome after surgical correction. Circulation 1989;80(04):840-845

8 Toro-Salazar OH, Steinberger J, Thomas W, Rocchini AP, Carpenter $\mathrm{B}$, Moller JH. Long-term follow-up of patients after coarctation of the aorta repair. Am J Cardiol 2002;89(05):541-547

9 Bambul Heck P, Pabst von Ohain J, Kaemmerer H, Ewert P, Hager A. Survival and cardiovascular events after coarctation-repair in long-term follow-up (COAFU): predictive value of clinical variables. Int J Cardiol 2017;228:347-351

10 Freed MD, Rocchini A, Rosenthal A, Nadas AS, Castaneda AR. Exercise-induced hypertension after surgical repair of coarctation of the aorta. Am J Cardiol 1979;43(02):253-258

11 Pelech AN, Kartodihardjo W, Balfe JA, Balfe JW, Olley PM, Leenen FH. Exercise in children before and after coarctectomy: hemodynamic, echocardiographic, and biochemical assessment. Am Heart J 1986;112(06):1263-1270

12 Presbitero P, Demarie D, Villani M, et al. Long term results (15-30 years) of surgical repair of aortic coarctation. Br Heart J 1987;57 (05):462-467

13 O'Sullivan JJ, Derrick G, Darnell R. Prevalence of hypertension in children after early repair of coarctation of the aorta: a cohort study using casual and 24 hour blood pressure measurement. Heart 2002;88(02):163-166

14 Hager A, Kanz S, Kaemmerer H, Schreiber C, Hess J. Coarctation Longterm Assessment (COALA): significance of arterial hypertension in a cohort of 404 patients up to 27 years after surgical repair of isolated coarctation of the aorta, even in the absence of restenosis and prosthetic material.J Thorac Cardiovasc Surg 2007;134(03):738-745

15 Daniels SR. Repair of coarctation of the aorta and hypertension: does age matter? Lancet 2001;358(9276):89

16 Boese JM, Bock M, Schoenberg SO, Schad LR. Estimation of aortic compliance using magnetic resonance pulse wave velocity measurement. Phys Med Biol 2000;45(06):1703-1713

17 Eichhorn JG, Krissak R, Rüdiger HJ, et al. Compliance of the normal-sized aorta in adolescents with Marfan syndrome: comparison of MR measurements of aortic distensibility and pulse wave velocity [in German]. RoFo Fortschr Geb Rontgenstr Nuklearmed 2007;179(08):841-846

18 Krug R, Boese JM, Schad LR. Determination of aortic compliance from magnetic resonance images using an automatic active contour model. Phys Med Biol 2003;48(15):2391-2404

19 Oshinski JN, Parks WJ, Markou CP, et al. Improved measurement of pressure gradients in aortic coarctation by magnetic resonance imaging. J Am Coll Cardiol 1996;28(07):1818-1826

20 Rijsterborgh H, Roelandt J. Doppler assessment of aortic stenosis: Bernoulli revisited. Ultrasound Med Biol 1987;13(05):241-248

21 Rao PS, Carey P. Doppler ultrasound in the prediction of pressure gradients across aortic coarctation. Am Heart J 1989;118(02): 299-307

22 Gutberlet M, Hosten N, Vogel M, et al. Quantification of morphologic and hemodynamic severity of coarctation of the aorta by magnetic resonance imaging. Cardiol Young 2001;11(05):512-520

23 VanAuker MD, Chandra M, Shirani J, Strom JA. Jet eccentricity: a misleading source of agreement between Doppler/catheter pressure gradients in aortic stenosis. J Am Soc Echocardiogr 2001;14 (09):853-862

24 Ou P, Celermajer DS, Mousseaux E, et al. Vascular remodeling after "successful" repair of coarctation: impact of aortic arch geometry. J Am Coll Cardiol 2007;49(08):883-890

25 Sahn DJ, DeMaria A, Kisslo J, Weyman A. Recommendations regarding quantitation in M-mode echocardiography: results of a survey of echocardiographic measurements. Circulation 1978; 58(06):1072-1083

26 Wühl E, Witte K, Soergel M, Mehls O, Schaefer F; German Working Group on Pediatric Hypertension. Distribution of 24-h ambulatory blood pressure in children: normalized reference values and role of body dimensions. JHypertens 2002;20(10):1995-2007 
e10 Aortic Coarctation a Systemic Vessel Disease Eichhorn et al.

27 Vigneswaran TV, Sinha MD, Valverde I, Simpson JM, Charakida M. Hypertension in coarctation of the aorta: challenges in diagnosis in children. Pediatr Cardiol 2018;39(01):1-10

28 Quail MA, Short R, Pandya B, et al. Abnormal wave reflections and left ventricular hypertrophy late after coarctation of the aorta repair. Hypertension 2017;69(03):501-509

29 Frydrychowicz A, Berger A, Russe MF, et al. Time-resolved magnetic resonance angiography and flow-sensitive 4-dimensional magnetic resonance imaging at 3 Tesla for blood flow and wall shear stress analysis. J Thorac Cardiovasc Surg 2008;136(02):400-407

30 LaDisa JF Jr, Dholakia RJ, Figueroa CA, et al. Computational simulations demonstrate altered wall shear stress in aortic coarctation patients treated by resection with end-to-end anastomosis. Congenit Heart Dis 2011;6(05):432-443

31 Canniffe C, Ou P, Walsh K, Bonnet D, Celermajer D. Hypertension after repair of aortic coarctation-a systematic review. Int J Cardiol 2013;167(06):2456-2461

32 McEniery CM, Yasmin, Wallace S, et al; ENIGMA Study Investigators. Increased stroke volume and aortic stiffness contribute to isolated systolic hypertension in young adults. Hypertension 2005;46(01): 221-226

33 Trojnarska O, Szczepaniak-Chicheł L, Mizia-Stec K, et al. Vascular remodeling in adults after coarctation repair: impact of descending aorta stenosis and age at surgery. Clin Res Cardiol 2011;100 (05):447-455
34 Nanton MA, Olley PM. Residual hypertension after coarctectomy in children. Am J Cardiol 1976;37(05):769-772

35 Kenny D, Polson JW, Martin RP, et al. Surgical approach for aortic coarctation influences arterial compliance and blood pressure control. Ann Thorac Surg 2010;90(02):600-604

36 Sophocleous F, Biffi B, Milano EG, et al. Aortic morphological variability in patients with bicuspid aortic valve and aortic coarctation. Eur J Cardiothorac Surg 2019;55(04):704-713

37 Donazzan L, Crepaz R, Stuefer J, Stellin G. Abnormalities of aortic arch shape, central aortic flow dynamics, and distensibility predispose to hypertension after successful repair of aortic coarctation. World J Pediatr Congenit Heart Surg 2014;5(04): 546-553

38 Dernellis J, Panaretou M. Aortic stiffness is an independent predictor of progression to hypertension in nonhypertensive subjects. Hypertension 2005;45(03):426-431

39 Ou P, Celermajer DS, Jolivet O, et al. Increased central aortic stiffness and left ventricular mass in normotensive young subjects after successful coarctation repair. Am Heart J 2008; 155(01): 187-193

40 Ou P, Celermajer DS, Raisky O, et al. Angular (Gothic) aortic arch leads to enhanced systolic wave reflection, central aortic stiffness, and increased left ventricular mass late after aortic coarctation repair: evaluation with magnetic resonance flow mapping.J Thorac Cardiovasc Surg 2008;135(01):62-68 